\section{Telangiectasia macularis eruptiva perstans: more than skin deep}

\author{
Casey E. Watkins, ${ }^{1}$ Winston B. Bokor, ${ }^{1}$ \\ Stuart Leicht, ${ }^{1,2}$ George Youngberg, ${ }^{1,3}$ \\ Guha Krishnaswamy 1,4,5
}

'East Tennessee State University, Quillen College of Medicine, Johnson City, TN; 2Department of Dermatology, Quillen College of Medicine, Johnson City, TN; ${ }^{3}$ Department of Pathology, Quillen College of Medicine, Johnson City, TN; ${ }^{4}$ Department Allergy and Immunology, Quillen College of Medicine, Johnson City, TN; ${ }^{5}$ Veterans Affairs Medical Center, Mountain Home, TN, USA
A case in point is systemic mastocytosis, which can present with a plethora of dermatological manifestations. TMEP is a rare form of cutaneous mastocytosis (CM) that can occasionally be associated with an underlying systemic mastocytosis (SM). ${ }^{1-3}$ Patients who present with this rare cutaneous disease should undergo routine testing to search for systemic disease. Development of additional morbidities, such as reactions to bee stings, systemic anaphylaxis, osteoporosis or bleeding secondary to heparin release from mast cells, may occur and may complicate the diagnosis, unless suspected. ${ }^{4-8}$ On occasion, the disease may evolve into a hematological malignancy, making early diagnosis, classification and monitoring an essential aspect of disease management. ${ }^{9}$

This review will discuss the diagnosis, pathology, pathogenesis and mast cell biology as well as the management of TMEP, complicated by systemic mastocytosis.

\section{Abstract}

Systemic mastocytosis is a rare disease involving the infiltration and accumulation of active mast cells within any organ system. By far, the most common organ affected is the skin. Cutaneous manifestations of mastocytosis, including Urticaria Pigmentosa (UP), cutaneous mastocytoma or telangiectasia macularis eruptive perstans (TMEP), may indicate a more serious and potentially life-threatening underlying disease. The presence of either UP or TMEP in a patient with anaphylactic symptoms should suggest the likelihood of systemic mastocytosis, with the caveat that systemic complications are more likely to occur in patients with UP. TMEP can usually be identified by the typical morphology, but a skin biopsy is confirmative. In patients with elevated tryptase levels or those with frequent systemic manifestations, a bone marrow biopsy is essential in order to demonstrate mast cell infiltration. Further genetic testing for mutations of $c$-kit gene or the FIP1L1 gene may help with disease classification and/or therapeutic approaches. Rarely, TMEP has been described with malignancy, radiation therapy, and myeloproliferative disorders. A few familial cases have also been described. In this review, we discuss the clinical features, diagnosis and management of patients with TMEP. We also discuss the possible molecular pathogenesis and the role of genetics in disease classification and treatment.

\section{Introduction}

Cutaneous eruptions can occasionally provide significant insight to underlying disease.

\section{Case Report}

A 43-year-old female was referred to the Allergy and Immunology Clinic by her primary care physician for evaluation of a persistent skin eruption. Worsening diffuse, erythematous skin eruptions that originated predominantly on the thighs and trunk region had been present for over a year. The lesions were described as itchy and raised at times but often appeared as merely discolorations of the skin. The rash waxed and waned periodically but had continued to spread and become generalized. The patient was evaluated by a dermatologist one year prior and a biopsy of the skin at that time was reported as benign. Twice daily loratadine was also started at that time with no change in the rash. Local treatments with steroid injections temporarily helped to alleviate the symptoms but the rash returned soon after. The patient could not pinpoint a single etiology. She had tried changing many environmental factors, including foods and detergents, to no avail. The patient had developed several episodes of systemic anaphylaxis associated with angioedema and flushing, but denied wheezing or syncope. She has otherwise been in good health with the exception of seasonal allergic rhinoconjunctivitis with sensitivity to dust, mold and pollen as well as a few instances of bronchitis and sinusitis.

Physical exam of the skin reveals a diffuse erythematous macular eruption with overlying dilated capillaries located on the thighs, upper extremities and back (Figure 1A, 1B). The patient was also found to have a very weakly positive Darier's sign (rubbing of the skin produces wheal and flare reaction with localized erythema, pruritis and edema). ${ }^{10,11}$ These exam findings were consistent with a diagno-
Correspondence: Casey E. Watkins, Quillen College of Medicine, Box 70580, Johnson City, TN, USA 37614.

E-mail:watkince@goldmail.etsu.edu

Key words: telangiectasia macularis eruptiva perstans, mastocytosis, SCORMA index, serum tryptase, D816V mutation.

Contributions: CEW, literature search, manuscript drafting, figures and tables creation, references management; WBB, literature search, manuscript drafting, final version proofreading; SL, manuscript revision for important clinical and dermatological content; GY, prepared the histological figures and legends and assisted in finalizing the manuscript; GK, manuscript drafting and final approval.

Conflict of interest: the authors report no conflicts of interest.

Received for publication: 27 June 2011.

Revision received: 6 July 2011.

Accepted for publication: 7 July 2011.

This work is licensed under a Creative Commons Attribution NonCommercial 3.0 License (CC BYNC 3.0).

(C) Copyright C.E. Watkins et al., 2011

Licensee PAGEPress, Italy

Dermatology Reports 2011; 3:e12

doi:10.4081/dr.2011.e12

sis of TMEP. Further work-up included a skin biopsy, complete blood count with differential, comprehensive chemistry panel, thyroid stimulating hormone levels, anti-nuclear antibody, rheumatoid factor, erythrocyte sedimentation rate, $\mathrm{C}$ reactive protein as well as serum tryptase and 24-hour urine histamine levels. In addition, allergy testing (Radioallergosorbent testing or RAST for specific IgE), levels of complement components (C3, C4) and serum immunoglobulins (immunoglobulins G, A, M and E) were obtained. Flow cytometry for Tand B- lymphocyte subsets (CD4, CD8, NKcells and CD19 positive B cells) was performed and plasma levels of interleukins 4,5 and 6 were analyzed with particular attention paid to interleukin 6 which correlates with mast cell burden. A bone marrow biopsy was performed to look for evidence of systemic mastocytosis. A bone density test was also scheduled to rule out osteoporosis which is commonly associated with mastocytosis.

Abnormalities noted from the extensive work-up included elevated serum tryptase level which was found to be $89.7 \mu \mathrm{g} / \mathrm{L}$ (reference range 0.4-19.9 $\mu \mathrm{g} / \mathrm{L}$ ) and an elevated 24-hour urinary histamine level of $79 \mathrm{ng} / 24$ hours (reference range, 13-62 ng/24 hours). A 3-mm punch biopsy of the right thigh showed superficial perivascular chronic inflammation. A 
mast cell tryptase immunohistochemical stain was used to identify mast cells (Figure 1C, 1D). Greater than 15 mast cells per perivascular high power field were observed. These findings are consistent with, and support the clinical diagnosis of, TMEP.

Bone marrow aspiration and core biopsy revealed $5-10 \%$ infiltration by mast cells, confirming the diagnosis of indolent systemic mastocytosis (ISM). Many of the mast cells within the aspirate were reported as hypogranular and some were spindle-shaped. Mast cell infiltrates were identified from ill-defined nodules within the bone marrow interstitium. CD117/c-KIT/Asp816Val mutation analysis of the bone marrow by polymerase chain reaction (PCR) was strongly positive. Fluorescent in situ hybridization (FISH) testing of CHIC2/PDGFRA/FIP1L1 gene regions was found to be within normal limits. No diagnostic features of an associated myeloproliferative neoplasm or myelodysplastic syndrome were identified. A mutated (and an unmutated) form of c-kit was detected in the patient by flow cytometry (Figure 2).

The patient was subsequently referred back to dermatology for psoralen plus ultraviolet A (PUVA) light therapy which alleviated cutaneous symptoms to some extent. The antihistamines loratadine, cetirizine and famotidine were all prescribed to the patient for daily use. A dual-emission x-ray absorptiometry (DEXA) was performed to look for signs of osteoporosis or other bone involvement. The patient was also instructed to follow Patterson protocol for IV contrast prophylaxis with any future contrast imaging studies. Two injectable epinephrine pens were also administered to the patient for prophylactic use with an anaphylactic episode. She has had two breakthrough anaphylactic episodes since the original diagnosis. At last follow up, the patient was seemingly doing well without anaphylactic reactions, but with persistent skin involvement.

\section{Materials and Methods}

Review of the medical records provided information about history, skin punch biopsies and histological examination, serum tryptase levels, 24-hour urinary histamine, extensive autoimmune testing, Radioallergosorbernt (RAST) testing and bone marrow biopsy. Cells obtained from bone marrow biopsy were tested for CD117/c-KIT/Asp816Val and FILP1/PDGFRA mutations. A thorough review of the literature was performed using PubMed/MeSH Database search. Available case reports and current review articles were investigated to provide up-to-date information about mastocytosis and TMEP. This case report has been approved by the East Tennessee State
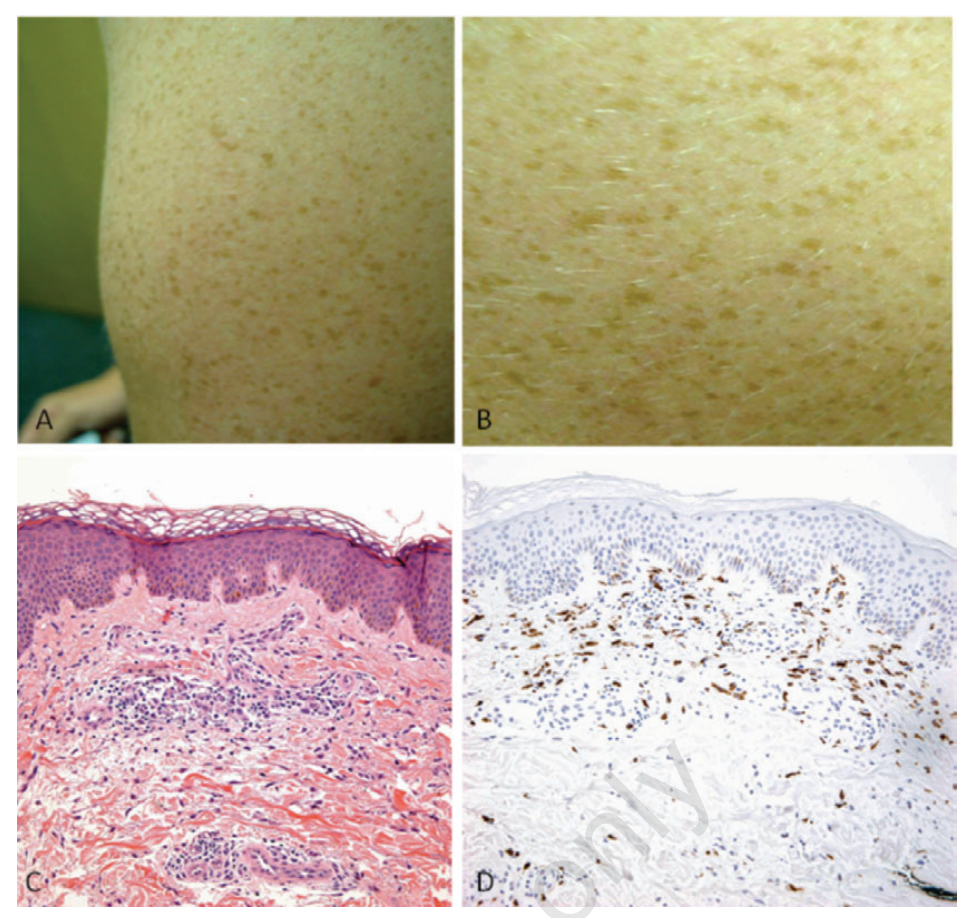

Figure 1. (A) Spontaneous telangiectasia macularis eruptiva perstans macular eruption. (B) Magnified view of the skin manifestations with small tan macules and red brown streaking. Images are produced with permission of the patient. (C) A cellular infiltrate is concentrated around superficial dermal blood vessels. Hematoxylin and eosin stain. 200x magnification. (D) The infiltrate demonstrates a substantial mast cell component $(>15$ per perivascular high power field). Many more mast cells are present than could be appreciated on the $\mathrm{H} \& \mathrm{E}$ stained section. Mast cell tryptase immunohistochemical stain. 200x magnification.

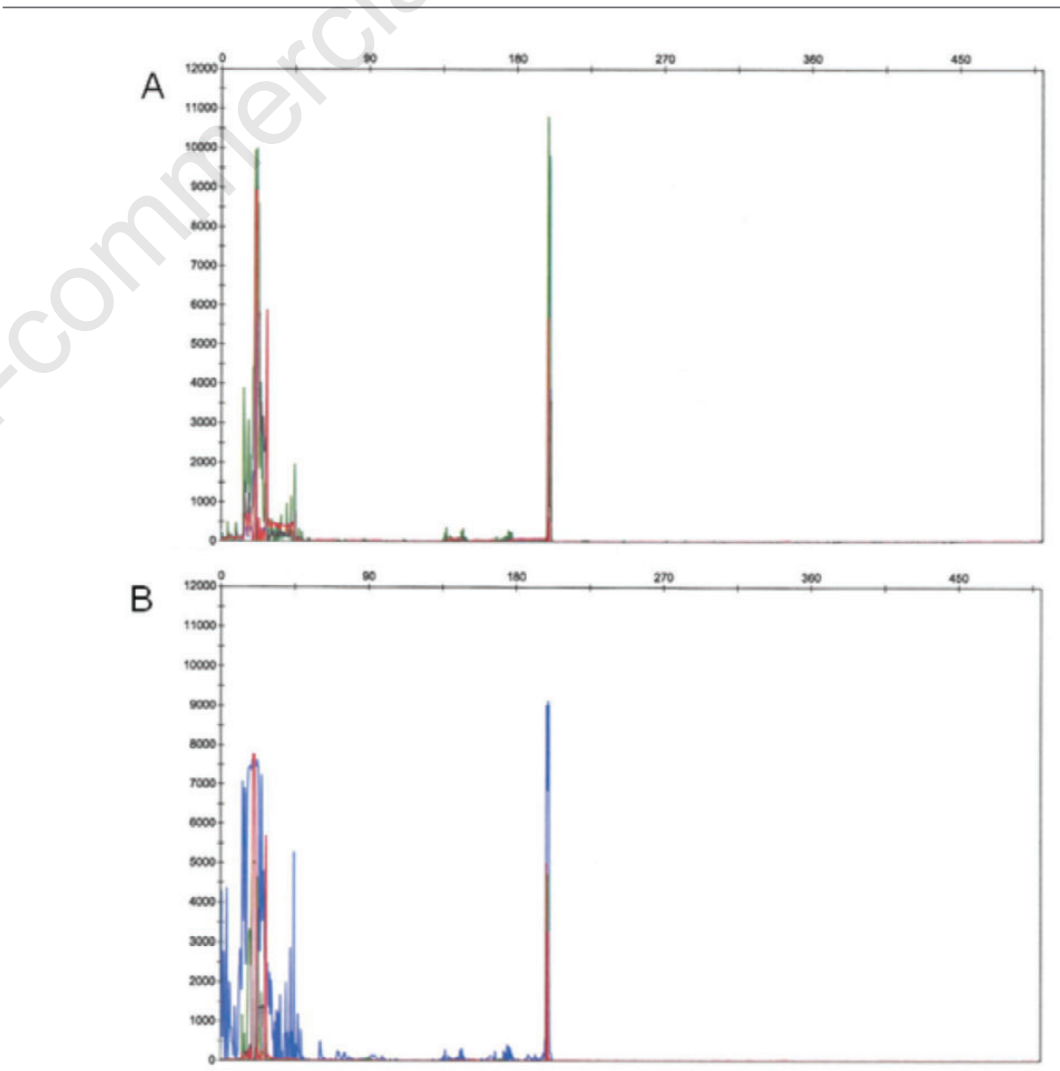

Figure 2. Flow cytometry used to detect c-kit mutation. Both non-mutated peaks (A) and mutated peaks $(\mathrm{B})$ were present in the patient. All patients with the c-kit mutation associated with mastocytosis should have some unmutated DNA present. These figures were kindly provided by Dr. Rebecca F. McClure of Mayo Clinic, Rochester, Minnesota. 
University (ETSU) and ETSU/Veterans Affairs Institutional Review Board. Patient consent was obtained for photographs and appropriate clinical procedures.

\section{Discussion}

Mastocytosis is a rare disease caused by an abnormal accumulation of mast cells in one or more organ systems. The most common organ affected by mastocytosis is the skin. ${ }^{12,13}$ Mastocytosis has a bimodal distribution with the majority of cases occurring in childhood and then peaking again at age 30-50 years. Men and women are affected equally but the Caucasian population is reported to be affected more commonly than any other race..$^{8,11}$ The true incidence and prevalence of mastocytosis is unknown. Studies suggest there are between $1 / 50,000$ and $1 / 150,000$ patients who present with mastocytosis per year. ${ }^{11,14}$

Mastocytosis encompasses a wide spectrum of disease processes ranging from purely cutaneous to indolent or aggressive systemic disease to malignancy or hematological disease..$^{15}$ More than 1 out of 4 adult patients with systemic disease also have cutaneous findings, therefore, recognizing the cutaneous manifestations of mastocytosis is an essential skill for clinicians. ${ }^{11,16}$ Systemic mastocytosis is diagnosed according to major and minor criteria. The single major criteria is multifocal dense aggregates of mast cells ( $>15$ MCs in aggregate) in bone marrow or another organ. The four minor criteria include abnormal morphology seen in $>25 \%$ of mast cells, $c$-kit mutation D816V, bone marrow mast cell expression of CD2 or CD25 and tryptase levels $>20 \mathrm{ng} / \mathrm{mL}^{17}$ The presence of either one major and one minor criteria or three minor criteria is required for diagnosis. The various forms of SM include Indolent Systemic Mastocytosis (ISM), Systemic Mastocytosis with an Associated Clonal Hematologic Non-Mast Cell Lineage Disease (SM-AHNMD), Aggressive Systemic Mastocytosis (ASM), Mast Cell Leukemia (MCL), Mast Cell Sarcoma (MCS) and Extracutaneous Mastocytoma (Table 1). ISM is the most common and was the form of SM observed in the patient presented in this report. Bone marrow is involved in nearly all cases of ISM, however, mast cell infiltrates are typically low $(<30 \%){ }^{1}$ ISM affects younger patients and has a good prognosis. Survival times are comparable to patients not affected by SM. ${ }^{17,18}$

\section{Systemic mastocytosis}

Mastocytosis, often presenting as dermatological disease, is classified according to the World Health Organization (WHO) Criteria released in $2001 .{ }^{17,19}$ There are six main cate- gories of mastocytosis which will be discussed in this article (Table 1). The diagnosis of CM, made by clinical observation and skin biopsy, is an indication for further evaluation of the patient to rule out SM. Serum tryptase levels and 24-hour urinary histamine levels are two common, non-invasive methods of looking for systemic involvement. A bone marrow biopsy is ultimately indicated to look for proliferation of mast cells and specific cytogenetic mutations. A specific mutation of the $c$-kit receptor on mast cells, referred to as Asp816Val or D816V, is the most common genetic mutation associated with mastocytosis (Figure 3). The bone marrow is probably the most common site of systemic involvement in the disease..$^{20}$ This may be attributed to the fact that mast cell progenitor cells originate in the bone marrow. Other organs may also be examined for systemic involvement, especially if organomegaly is present.

Yearly complete blood count, comprehensive metabolic panel, serum tryptase levels and 24hour urinary histamine levels should be obtained to follow disease progression. There is a possibility of transformation to mast cell leukemia or other hematological malignancy in all patients with mastocytosis.

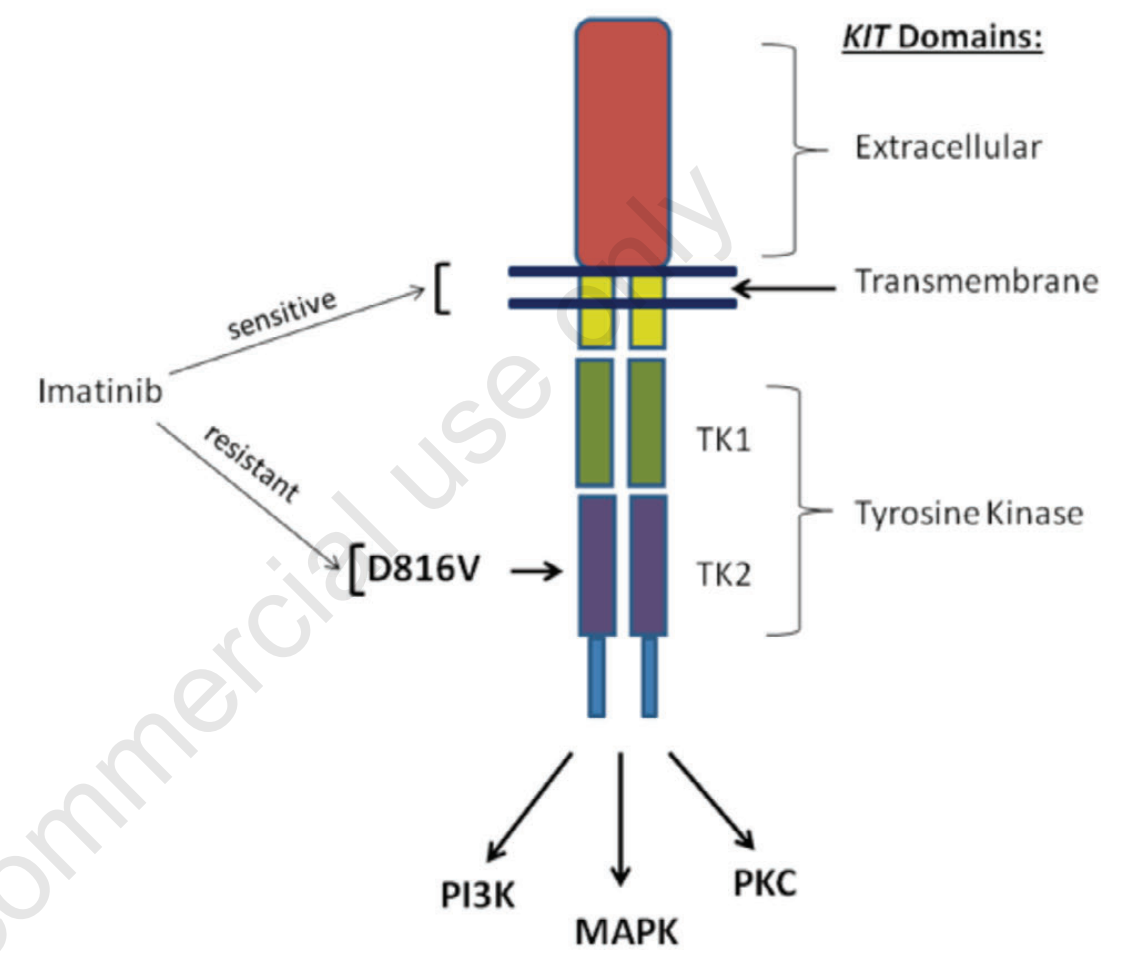

Figure 3. Schematic diagram of c-kit tyrosine kinase receptor. The most common mutations, particularly the D816V mutation, that result in mastocytosis affect this specific protein on mast cells.

Table 1. WHO Classification of Mastocytosis. The official WHO classification system which is based on the concensus classification for mastocytosis proposed in 2001. ${ }^{19}$ This classification system and its criteria enable differentiation among the multiple forms of mastocytosis. Common abbreviations are also listed for reference. *Most common manifestation.

Cutaneous Mastocytosis

$\mathrm{CM}$

Maculopapular cutaneous mastocytosis

Urticaria pigmentosa*

Telangiectasia macularis eruptiva perstans

UP/MPCP

Diffuse cutaneous mastocytosis

TMEP

Mastocytoma of the skin

Indolent systemic mastocytosis

DCM

Smoldering mastocytosis

Isolated bone marrow mastocytosis

Systemic mastocytosis with an associated clonal hematologic non-mast cell lineage disease SM-AHNMD Aggressive systemic mastocytosis $\quad$ ASM

$\begin{array}{ll}\text { Mast cell leukemia } & \text { MCL }\end{array}$

Mast cell sarcoma $\quad$ MCS

Extracutaneous mastocytoma 


\section{Cutaneous mastocytosis}

According to the World Health Organization (WHO) classification, CM is divided into urticaria pigmentosum or maculopapular cutaneous mastocytosis (UP/MPCM), diffuse cutaneous mastocytosis (DCM), and mastocytoma of the skin (Table 2). UP/MPCM is present in the vast majority of $\mathrm{CM}$ cases. It presents with a maculopapular rash and positive Darier's sign. The three subvariants of UP/MPCM are a plaque form, a nodular form and a telangiectectatic form known as TMEP.1,17,21 DCM presents with a diffuse erythrodermic rash and the skin may be diffusely thickened. Mastocytomas are usually solitary or few, less than $1 \mathrm{~cm}$ in diameter and reddish or yellow in color. By definition, CM is restricted to the skin so wherever extracutaneous involvement exists, the diagnosis is SM. Pure CM is most common in children. Many adults with cutaneous disease actually have an underlying SM.

\section{Telangiectasia macularis eruptiva perstans}

TMEP is a very rare cutaneous finding seen in less than one percent of patients with mastocytosis. ${ }^{16,22-24}$ It was first described in the 1930s by Parks Weber. ${ }^{25}$ The lesions of TMEP typically appear as small, irregular reddishbrown telangiectatic macules overlying tan to brown background. Individual lesions are usually between 2 and $4 \mathrm{~mm}$ in diameter. ${ }^{16}$ The telangiectatic lesions will classically blanch on diascopy. One study discussed the use of dermatoscopy to identify telangiectatic vessels arranged in a reticular pattern; these findings are considered unique to and characteristic of TMEP. $^{21}$ Lesions are typically located on the trunk and proximal extremities in a symmetrical pattern and are non-pruritic. Palms, soles and face are spared in most cases. Darier's sign, a common finding of UP/MPCM, is typi- cally negative or slight in patients with TMEP due to the relatively smaller number of mast cells involved. ${ }^{8,16}$ Diagnosis is usually based on clinical exam and confirmed by skin biopsy with histological examination.

Histologically, TMEP typically involves only a slight increase in mast cells with infiltration of the superficial dermis and epidermal hyperpigmentation. ${ }^{16}$ Mast cells are primarily located around dilated capillaries and venules of the superficial venous plexus found in the upper third of the dermis. ${ }^{21,22,26,27}$ Giemsa and toludine-blue stains highlight the metachromatic intracytoplasmic granules and are good for recognizing mast cells. ${ }^{20}$ Immunohistochemical staining for $c$ - $k$ it and/or tryptase is more sensitive and may also be used to confirm the diagnosis (Figure 1D).22

Unlike the other forms of CM, TMEP most commonly manifests in adulthood. There have been reports of TMEP in children, infants and familial cases but these are extremely rare..$^{27,28}$ TMEP is traditionally thought to be restricted to the skin, however, it has been reported in association with SM. ${ }^{10,29}$ Bone marrow, gastrointestinal tract, liver, spleen and lymph node involvement have all been described in patients with TMEP. ${ }^{22}$ Systemic involvement should always be suspected if symptoms such as flushing, diarrhea, dyspnea, tachycardia, pruritis, syncope or signs of anaphylaxis are present in addition to the characteristic skin lesions. ${ }^{26}$ One study suggests bone marrow biopsy and aspirates should be routine in all adult patients with CM for baseline staging purposes. ${ }^{30} \mathrm{CM}$ is commonly restricted to the skin in children and adolescents. It is not necessary to perform bone marrow biopsy in these patients without symptomatic indications or abnormal tests. Serum tryptase and 24-hour urine histamine are good preliminary tests to investigate for systemic involvement. ${ }^{17}$

Some cases of TMEP have been described as familial, with a clustering within families. ${ }^{27,31}$
There have been rare cases described in patients undergoing radiation, in patients with breast or renal carcinoma, ${ }^{32}$ malignant melanoma, ${ }^{33}$ or in patients with Sjogrens syndrome. ${ }^{34}$ Other cases have been described in patients with multiple myeloma, ${ }^{35}$ myeloproliferative disorders (such as Polycythemia Rubra Vera $)^{36}$ and in association with leukemia or myelofibrosis. ${ }^{9,37,38}$ Coexistence of UP and TMEP has also been described in rare cases $^{37,39-41}$ On occasion, TMEP may present as unexplained pruritis. ${ }^{42}$ Some cases of TMEP may present in atypical locations such as unilaterally on the face ${ }^{43,44}$ and/or localized to the upper arms. ${ }^{26}$ Neurological complications such as prolonged loss of consciousness or the Kounis-like phenomenon have also been described. ${ }^{45}$

\section{Diagnosis and evaluation}

Due to the range of organs that can be affected as well as the esoteric nature of the symptoms of systemic disease, the diagnosis may be missed for years. Delay in diagnosis may put patients at risk for life-threatening events including anaphylaxis and histaminemediated vascular collapse.,12,13,46 Skin findings suggestive of cutaneous mastocytosis should be biopsied to confirm clinical suspicions. Avoid the use of local anesthetic containing epinephrine during skin biopsy due to the ability of epinephrine to stimulate mast cell degranulation. Adults who present with cutaneous forms of mastocytosis should also be carefully considered for further investigation into an underlying systemic disease..$^{17,30}$ Systemic symptoms of mastocytosis may occasionally mimic carcinoid syndrome, which should be considered in the differential diagnosis. Strategies for diagnosing mastocytosis are discussed in Table 3.

Tryptase, the main protein component of the secretory granules found within mast cells, is a good indicator of total mast cell burden. ${ }^{15}$ In

Table 2. Telangiectasia macularis eruptive perstans and other cutaneous mastocytoses. A brief summary of the prominent clinical, histopathological and demographic descriptors of telangiectasia macularis eruptive perstans as well as the other forms of cutaneous mastocytosis.

\begin{tabular}{|c|c|c|c|}
\hline CM & Clinical findings & Pathological findings & Demographics \\
\hline TMEP & $\begin{array}{l}\text { Red-brown, maculo-papular, telangiectatic, } \\
\text { irregular, 2-6 mm. Located on trunk } \\
\text { \& extremities. Darier's sign negative or slight. }\end{array}$ & $\begin{array}{l}\text { Subtle increase in MC, perivascular } \\
\text { location, upper } 1 / 3 \text { of dermis, dilated } \\
\text { superficial capillaries. }\end{array}$ & $\begin{array}{l}\text { Almost exclusively in adults. } \\
\text { Seen in }<1 \% \text { of patients with mastocytosis. }\end{array}$ \\
\hline UP & $\begin{array}{l}\text { Red-brown, maculo- papular rash, } \\
\text { 0.5-3.5 mm, flushing, pruritis, } \\
\text { positive Darier's sign, dermatographism. }\end{array}$ & Increased number of mature MC. & $\begin{array}{l}\text { Presents at any age, peak incidence in childhood } \\
\text { and again in 3rd decade of life. } \\
\text { Most common CM. }\end{array}$ \\
\hline Mastocytoma & $\begin{array}{l}\text { Red-brown nodules or plaques, } \\
\text { usually }<1 \mathrm{~cm} \text {, positive Darier's sign. }\end{array}$ & $\begin{array}{l}\text { Large, solitary collection of densely } \\
\text { packed MC. }\end{array}$ & $\begin{array}{l}\text { Most appear in first } 3 \text { months of life. } \\
\text { Rare in adults. }\end{array}$ \\
\hline DCM $^{*}$ & $\begin{array}{l}\text { Thickened red-brown edematous skin, } \\
\text { orange-peel texture, positive Darier's sign, } \\
\text { dermatographism. }\end{array}$ & $\begin{array}{l}\text { Diffuse, generalized band-like } \\
\text { infiltration of MC. }\end{array}$ & Present before age 3. \\
\hline
\end{tabular}


general, most patients with pure CM exhibit normal serum tryptase levels. Tryptase levels > $20 \mu \mathrm{g} / \mathrm{L}$ are typically seen with SM. ${ }^{20,47}$ Elevated 24-hour urinary histamine is another common finding associated with systemic mastocytosis but is non-specific. The metabolite of histamine, N-methylhistamine, is a more sensitive test and should be used when possible. ${ }^{15}$

A practical tool for the evaluation of $\mathrm{CM}$ is the SCORMA (SCORing MAstocytosis) Index (Table 4). It consists of three parts: (A) the extent of skin affected expressed as a percent, (B) the intensity of the skin abnormality based on pigmentation/erythema, vesiculation, elevation and Darier's sign and (C) five subjective symptoms which include triggers, flushing, diarrhea, pruritis and bone pain. These parts are each scored and applied to a formula to calculate the final SCORMA Index. This clinical tool may be useful to initially evaluate severity. It is considered comparable to serum tryptase levels in predicting systemic involvement. SCORMA Index is also an excellent method for monitoring disease progression and treatment efficacy. ${ }^{47}$

In general, patients with cutaneous lesions have a good prognosis despite involvement of other organs. ${ }^{11}$ This fact may be attributed to tendency for earlier diagnosis if skin lesions are present and predilection of skin disease with ISM, which in itself has a better prognosis than the other types of SM. ISM has a prolonged clinical course with survival times estimated at two decades and more if transformation into another disease category does not occur. ${ }^{20}$

\section{Cytogenetics and molecular aspects}

Essential aspects of mast cell biology and the role of these cells in the immune-inflammatory response has been reviewed by us. ${ }^{48-50}$ The relationship between mast cells and $\mathrm{T}$ cells, fibroblasts and eosinophils have impor-

Table 3. Diagnostic strategies in telangiectasia macularis eruptive perstans and/or suspected mastocytosis. Summary of diagnostic strategies that may be employed when mastocytosis is suspected.

\section{For patients with TMEP or UP}

Skin biopsy

Complete blood count and differential

Comprehensive chemistry

Serum tryptase level

Bone marrow biopsy with evaluations for mutations*

\section{For patients with suspected systemic mastocytosis}

Urine collection for biochemical testing

Bone scan

DEXA study/bone mineral density

Gastrointestinal endoscopy (for GI tract symptoms or diarrhea)

Tissue biopsy (for involved sites such as liver or GI mucosa)

Computed tomography of the abdomen, chest and/or pelvis

Exclude other disease presenting in a similar fashion (flushing, diarrhea, wheezing, hypotension) Carcinoid syndrome (Urine 5-HIAA)

TMEP, telangiectasia macularis eruptiva perstans; UP, urticaria mastocytosis; DEXA, Dual-energy X-ray absorptiometry; GI, gastrointestinal; 5-HIAA, 5-hydroxyindoleacetic acid. *Mutations including c-kit (D816V) and FIPIL1.

Table 4. SCORMA Index. The clinical components of the SCORMA Index. The severity of cutaneous mastocytosis can be evaluated using the listed criteria. It may also be used as a tool for disease surveillance. ${ }^{47}$

\begin{tabular}{|c|c|c|}
\hline Part A & $\begin{array}{l}\text { Extent of skin abnormality } \\
\text { present on physical examination. }\end{array}$ & $\begin{array}{l}\text { Measured as percent body surface area } \\
\text { involved. }\end{array}$ \\
\hline Part B & $\begin{array}{l}\text { 1. Pigmentation/erthyema } \\
\text { 2. Vesiculation } \\
\text { 3. Elevation } \\
\text { 4. Positive Darier's sign }\end{array}$ & $\begin{array}{l}\text { Measured according to examiners' observation. } \\
\text { Absent }=0 \text {, mild }=1 \text {, moderate }=2 \text {, severe }=3 \text {. }\end{array}$ \\
\hline Part C & $\begin{array}{l}\text { 1. Provoking Factor(s) } \\
\text { 2. Flushing } \\
\text { 3. Diarrhea } \\
\text { 4. Pruritis } \\
\text { 5. Localized bone pain }\end{array}$ & $\begin{array}{l}\text { Subjective severity of symptoms } \\
\text { reported by the patient on a scale of 1-10. }\end{array}$ \\
\hline SCORMA 9ndex & $=\mathrm{A} / 4+5 \mathrm{~B}+2 \mathrm{C} / 5$ & Scores range from 5.2 to 100 \\
\hline
\end{tabular}

tant implications for disease pathogenesis. ${ }^{51-53}$ Mast cells can be activated by a variety of procceses, including antigens (such as venom stings or food allergens), cytokines as well as by some bacteria. ${ }^{54-57}$ The involvement of mitogen-activated protein kinase (MAPK) and nuclear factor kappa B (NF-KB) pathway in signaling may explain the efficacy of drugs such as the glucocorticoids in some complications. These aspects may also explain the complications of bee stings or drug/food reactions in patients with mastocytosis, and the resultant recommendation of avoidance of contact with some of these triggers. ${ }^{4,8,46} \mathrm{~A}$ list of triggers in SM is provided in Table 5.

An important genetic component of mastocytosis involves a mutation in the type III transmembrane tyrosine kinase receptor $c$-kit (Figure 3). This receptor has an extracellular domain that binds to mast cell growth factor which functions to promote growth and functionality of mast cells. ${ }^{16}$ The most common type of mutation occurs within codon 816 (known as $\mathrm{D} 816 \mathrm{~V}$ ) and causes constitutive activation of the $c$-kit receptor. ${ }^{10}$ Testing for the D816V mutation can be done on bone marrow biopsy, as was performed in the case described, or on skin biopsy. This mutation does not differentiate cutaneous and extracutaneous involvement but is found in nearly all adult cases of systemic mastocytosis. ${ }^{10,15}$ Many promising drugs that specifically target mast cells and the c-kit receptor are currently under investigation, including PKC412, AMN107 and dasa-

Table 5. Triggers that can activate mast cells. Physical stimuli and substances that can activate mast cells. These may be considered triggers for systemic symptoms or anaphylaxis in patients with mastocytosis.

Alcohol

Bacterial toxins

Emotional stress

Exercise

Food allergens (e.g., shellfish, peanuts)

Immunologic stimuli (e.g., IgE)

Sunlight

Temperature extremes

Venoms (e.g., hymenoptera)

Pharmaceutical agents

Acetylsalicylic acid

Amphotericin B

d-Tubocurarine

Dextromethorphan

Gallium

Narcotics (e.g., morphine, meperidine, codeine)

Nonsteroidal anti-inflammatory drugs

Polymyxin B

Polymeric eye drops

Quinine

Radiographic contrast containing iodine

Reserpine

Scopolomine 
tinib. ${ }^{20} \mathrm{~A}$ less common mutation located in the Fip1-like 1 gene (FIP1L1) is routinely tested for in patients with SM because it is a good indicator of response to treatment with the targeted tyrosine kinase inhibitor Imatinib. ${ }^{?}$

Constitutive signaling resulting from any mutation leads to uncontrolled proliferation of mast cells. Increased release of the $c$-kit ligand, known as mast cell growth factor (MCGF) or stem cell factor (SCF), may also contribute by acting locally to cause mast cell proliferation. Additionally, MCGF has been shown to cause melanocyte proliferation with increased production of melanin pigment. This likely accounts for the hyperpigmentation typical of UP/MPCM lesions. ${ }^{21}$ Subsequent localized release of mast cell mediators and angiogenic factors from the activated mast cells can cause permanent vasodilation. This mechanism is responsible for the telangiectasias and erythematous nature of the lesions seen with TMEP. ${ }^{26}$ Systemic release of excess mast cell mediators causes the clinical signs and symptoms of mastocytosis.

Some of the main mast cell mediators include histamine, heparin, tryptase, leukotrienes and interleukins. Histamine causes vasodilation, erythema, edema, pruritis and increased gastric acid. ${ }^{13}$ Heparin and tryptase are both thought to be involved in the premature development of osteoporosis in patients with SM. These two factors are also responsible for inhibition of coagulation and possible increased bleeding risk. Leukotrienes are involved in bronchoconstriction and increased vascular permeability. ${ }^{13}$ Treatment at this time most commonly consists of modulating the effects of these mast cell mediators.

\section{Treatment}

There is no established first-line therapy for TMEP or systemic mastocytosis and much of treatment is focused on symptomatic relief. The literature suggests a combination of avoidance of triggers, limiting release of mast cell mediators and blocking the effects of these mediators. ${ }^{58}$ The more aggressive forms, including ASM and MCL, may require a more intensive therapeutic regimen. Cytoreductive and chemotherapeutic agents may be required in such cases.

Common triggers for patients with mastocytosis (Table 5) include alcohol, exercise, extreme temperatures, venoms, aspirin, nonsteroidal anti-inflammatory drugs, anesthesia and narcotics. ${ }^{7,13}$ Patients should be educated about exposure to triggers and should be managed on an individual basis.

For cutaneous manifestations, oral psoralen plus UVA photochemotherapy, high-dose UVA1 and narrow-band ultraviolet B phototherapy (UVB) have all proven beneficial both cosmetically and symptomatically. $22,59,60$ Surgery with

Table 6. Treatment of telangiectasia macularis eruptive perstans and systemic mastocytosis. Mast cell components that cause typical symptoms of mastocytosis and how to treat based on symptomatology.

\begin{tabular}{lll} 
Component & Symptom & \multicolumn{1}{c}{ Treatment } \\
Mast cell & Plethora & Cromoglycate \\
Histamine & Vasodilation & $\mathrm{H}_{1}$ receptor antagonists \\
& Excess gastric acid & $\mathrm{H}_{2}$ receptor antagonists \\
\hline Tyrosine kinase & Mast cell proliferation & Imatinib and congeners \\
NF-kB & Inflammation & Glucocorticoids \\
\hline LTC4 & Inflammation & Leukotriene inhibitors \\
Multiple mediators & Hypotension & Epinephrine/autoinjectors \\
\hline Mast cell proliferation & Systemic disease & Biological agents \\
& & (e.g., interferon $\alpha$ ) \\
Mast cell infiltration & UP/TMEP & PUVA (phototherapy) \\
& Mastocytoma & Excision \\
\hline
\end{tabular}

TMEP, telangiectasia macularis eruptiva perstans; SM, systemic mastocytosis; NF-кB, nuclear factor kappa B; LTC4, leukotriene C4; UP, urticaria pigmentosa; PUVA, psoralens and ultraviolet A.

$585 \mathrm{~nm}$ flashlamp-pumped dye laser is also thought to improve cutaneous symptoms. ${ }^{61}$ In nearly all cases, the symptom relief was transient and therapy had to be repeated. If pure $\mathrm{CM}$ is diagnosed, observation and conservative management of skin lesions is reasonable. With underlying SM, treatment of systemic disease is reported to provide relief of cutaneous symptoms as well.

Antihistamines are a well-established option for symptoms of SM. H1-histaminereceptor antagonists are used for pruritis and urticaria and $\mathrm{H} 2$ antagonists for excess gastric acid secretion. ${ }^{62,63}$ The anti-mediator drug ketotifen may also be used to relieve pruritis, urticaria, flushing and bone pain.1,10 Additionally, leukotriene receptor antagonists have proven successful for short-term control of mediator-induced symptoms. ${ }^{58,64}$ Agents that stabilize mast cells, such as oral disodium cromoglycate, are used to block the release of mediators and decrease pruritis and flushing. Oral cromolyn sodium appears to work particularly well for gastrointestinal symptoms. .5-67 $^{65}$ Corticosteroids, both intravenous and topical, have also been used and may be beneficial in patients with frequent hypotensive episodes. ${ }^{20}$ Topical steroids may help to alleviate skin symptoms. Table 6 demonstrates treatment options with respect to mediator-related symptoms. Interferon- $\alpha$, immunosuppressants and other cytoreductive agents have been reported as possible treatments for more severe and aggressive forms of mastocytosis. ${ }^{20,68,69}$

Prophylactic measures should also be taken in patients with SM. Patients should be educated about common triggers, risks with surgery and using the Patterson Protocol for procedures involving IV contrast due to the increased risk of anaphylaxis. Providing patients with epinephrine injections for emergency use in cases of anaphylaxis or episodes of hypotension is highly recommended. ${ }^{5}$ DEXA scans should also be obtained due to the high- er risk of osteopenia and osteoporois in these patients. Also encourage careful follow-up with yearly monitoring of $\mathrm{CBC}$, serum tryptase and 24-hour urinary histamine for disease surveillance.

Investigation into the cytogenetics of mastocytosis continues to reveal encouraging treatment targets. Imatinib may be used as treatment for SM, however, the D816V mutation is an indicator of poor response to this therapy. Only patients with the FIP1L1 mutation have been shown to have a good response to Imatinib therapy. ${ }^{7}$ Increasing knowledge of the genetics of mastocytosis enables progression of treatment options. The most promising agents appear to be those that specifically target the $c$-kit kinase receptor on mast cells. Therapies targeting the specific cytogenetics of mastocytosis have potential to be the first and only curative modality. Further research and development in this field is needed.

\section{Conclusions}

Characteristic skin findings can sometimes indicate the need for a high index of suspicion for an underlying systemic illness. It is essential to recognize and investigate cutaneous manifestations of diseases, especially those that may prove potentially fatal. Mastocytosis is a rare disease that most commonly presents with cutaneous manifestations. The symptoms of mastocytosis are caused by release of mediators from mast cells that may cause, in severe cases, anaphylaxis or histamine-mediated vascular collapse.

Progressing, eruptive erythematous lesions with reddish-brown macules and telangiectasias of the trunk and extremities are seen with telangiectasia macularis eruptive perstans (TMEP), a rare form of maculopapular cutaneous mastocytosis. Further work-up 
should be initiated, especially in adult patients with new-onset skin manifestations of mastocytosis, in order to look for systemic involvement.

Treatment options include but are not limited to phototherapy (PUVA and UVB), antihistamines $\left(\mathrm{H}_{1}\right.$ and $\mathrm{H}_{2}$ blockers $)$ and injectable epinephrine due to the increased risk for anaphylaxis. Yearly complete blood count, comprehensive metabolic panel, serum tryptase levels, 24hour urine histamine and SCORMA Index are excellent options for disease surveillance and monitoring response to treatment. Patients should be followed closely due to the possibility of transformation to mast cell leukemia or other hematological malignancy. Due to the prevalence of the $\mathrm{D} 816 \mathrm{~V}$ mutation in adults with mastocytosis, further investigation into cytogenetics and targeted therapy is promising.

\section{References}

1. Valent P, Horny HP, Escribano L, et al. Diagnostic criteria and classification of mastocytosis: a consensus proposal. Leuk Res 2001;25:603-25.

2. Briley LD, Phillips CM. Cutaneous mastocytosis: a review focusing on the pediatric population. Clin Pediatr (Phila) 2008;47:757-61.

3. Gibbs NF, Friedlander SF, Harpster EF. Telangiectasia macularis eruptiva perstans. Pediatr Dermatol 2000;17:194-7.

4. Biedermann T, Rueff F, Sander CA, et al. Mastocytosis associated with severe wasp sting anaphylaxis detected by elevated serum mast cell tryptase levels. Br J Dermatol 1999;141:1110-2.

5. Brockow K, Jofer C, Behrendt H, et al. Anaphylaxis in patients with mastocytosis: a study on history, clinical features and risk factors in 120 patients. Allergy 2008;63:226-32.

6. Brouet JC. Anaphylaxis and systemic mastocytosis. J Clin Pathol 1979;32:854.

7. Murali MR, Castells MC, Song JY, et al. Case records of the Massachusetts General Hospital. Case 9-2011. A 37-yearold man with flushing and hypotension. $\mathrm{N}$ Engl J Med 2011;364:1155-65.

8. Vidal C, Del RE, Suarez-Penaranda J, et al. Telangiectasia macularis eruptiva perstans presented as a pseudoallergic food reaction. J Investig Allergol Clin Immunol 2000;10:248-50.

9. Mahadeo KM, Wolgast L, McMahon C, et al. Systemic Mastocytosis in a Child With $\mathrm{t}(8 ; 21)$ Acute Myeloid Leukemia. Pediatr Blood Cancer 2011. [Epub ahead of print]

10. Soter NA. Mastocytosis and the skin. Hematol Oncol Clin North Am 2000;14:537-
55.

11. Hartmann K, Henz BM. Mastocytosis: recent advances in defining the disease. Br J Dermatol 2001;144:682-95.

12. Pardanani A, Lim KH, Lasho TL, et al. WHO subvariants of indolent mastocytosis: clinical details and prognostic evaluation in 159 consecutive adults. Blood 2010;115: $150-1$.

13. Alto WA, Clarcq L. Cutaneous and systemic manifestations of mastocytosis. Am Fam Physician 1999;59:3047-60.

14. Vano-Galvan S, De la Hoz B, Nunez R, et al. Indolent systemic mastocytosis. Isr Med Assoc J 2010;12:185-7.

15. Liu AY, Lowe RC, Levy BD, et al. Clinical problem-solving. A rash hypothesis. N Engl J Med 2010;363:72-8.

16. Wolff K, Komar M, Petzelbauer P. Clinical and histopathological aspects of cutaneous mastocytosis. Leuk Res 2001;25:519-28.

17. Valent $P$, Akin C, Sperr WR, et al. Mast cell proliferative disorders: current view on variants recognized by the World Health Organization. Hematol Oncol Clin North Am 2003;17:1227-41.

18. Lim KH, Tefferi A, Lasho TL, et al. Systemic mastocytosis in 342 consecutive adults: survival studies and prognostic factors. Blood 2009;113:5727-36.

19. Valent P, Akin C, Escribano L, et al. Standards and standardization in mastocytosis: consensus statements on diagnostics, treatment recommendations and response criteria. Eur J Clin Invest 2007;37:435-53.

20. Horny HP, Sotlar K, Valent P. Mastocytosis: state of the art. Pathobiology 2007;74:12132.

21. Akay BN, Kittler H, Sanli H, et al. Dermatoscopic findings of cutaneous mastocytosis. Dermatology 2009;218:226-30.

22. Sotiriou E, Apalla Z, Ioannides D. Telangiectasia macularis eruptive perstans successfully treated with PUVA therapy. Photodermatol Photoimmunol Photomed 2010;26:46-7.

23. Chung-Leddon J. Telangiectasia macularis eruptiva perstans. Dermatol Online J 2000;6:6.

24. Oliveira CR, Albuquerque GC, Simon EF, et al. [Case for diagnosis. Telangiectasia macularis eruptiva perstans]. An Bras Dermatol 2009;84:87-9.

25. Nguyen NQ. Telangiectasia macularis eruptiva perstans. Dermatol Online $\mathrm{J}$ 2004;10:1.

26. Betti R, Vergani R, Tolomio E, et al. Guess what! Telangiectasia macularis eruptiva perstans involving the upper arms in an adult male. Eur J Dermatol 2000;10:563-4.

27. Neri I, Guareschi E, Guerrini V, et al. Familial telangiectasia macularis eruptiva perstans. Pediatr Dermatol 2005;22:488-9.

28. Kalayciyan AK, Kotogyan A. Telangiectasia macularis eruptiva perstans. J Eur Acad Dermatol Venereol 2001;15:263-4.

29. Cohn MS, Mahon MJ. Telangiectasia macularis eruptiva perstans. J Am 0steopath Assoc 1994;94:246-8.

30. Tebbe B, Stavropoulos PG, Krasagakis K, et al. Cutaneous mastocytosis in adults. evaluation of 14 patients with respect to systemic disease manifestations. Dermatology 1998;197:101-8.

31. Chang A, Tung RC, Schlesinger T, et al. Familial cutaneous mastocytosis. Pediatr Dermatol 2001;18:271-6.

32. Pascual JC, Banuls J, Albares MP, et al. Presentation of telangiectasia macularis eruptiva perstans as a long-standing solitary plaque associated with renal carcinoma. J Cutan Med Surg 2003;7:399-402.

33. Kowalzic L, Eickenscheidt L, Seidel C, et al. Telangiectasia macularis eruptiva perstans, a form of cutaneous mastocytosis, associated with malignant melanoma. J Dtsch Dermatol Ges 2009;7:360-2.

34. Kalay ES, Stewart C, Hassanein A, et al. Cutaneous mastocytosis in a patient with primary Sjogren's syndrome. J Rheumatol 2006;33:1697-700.

35. Bachmeyer C, Guillemette J, Blum L, et al. Telangiectasia macularis eruptiva perstans and multiple myeloma. J Am Acad Dermatol 2000;43:972-4.

36. Suzuki K, Konishi N, Tokura Y, et al. Telangiectasia macularis eruptiva perstans in polycythemia rubra vera. Eur $\mathrm{J}$ Dermatol 2002;12:201-3.

37. Turchin I, Barankin B, Schloss E. Unusual cutaneous findings of urticaria pigmentosa and telangiectasia macularis eruptiva perstans associated with marked myelofibrosis. Int J Dermatol 2006;45:1215-7.

38. Martin LK, Romanelli P, Ahn YS, et al. Telangiectasia macularis eruptiva perstans with an associated myeloproliferative disorder. Int J Dermatol 2004;43:922-4.

39. Parks A, Camisa C. Reddish-brown macules with telangiectasia and pruritus. Urticaria pigmentosa-telangiectasia macularis eruptiva perstans (TMEP) variant, with systemic mastocytosis. Arch Dermatol 1988;124:429-3.

40. Forman L. Urticaria Pigmentosa in an Adult (Telangiectasia Macularis Eruptiva Perstans, Barber and Parkes Weber Type). Proc R Soc Med 1943;36:291.

41. Weber FP. Telangiectasia Macularis Eruptiva Perstans-probably a telangiectatic variety of urticaria pigmentosa in an adult. Proc R Soc Med 1930;24:96-7.

42. Rishpon A, Matz H, Gat A, et al. Telangiectasia macularis eruptiva perstans: unusual presentation and treatment. Skinmed 2006;5:300-2. 
43. Fried SZ, Lynfield YL. Unilateral facial telangiectasia macularis eruptiva perstans. J Am Acad Dermatol 1987;16:250-2.

44. Gonzalez-Castro U, Luelmo-Aguilar J, Castells-Rodellas A. Unilateral facial telangiectasia macularis eruptiva perstans. Int J Dermatol 1993;32:123-4.

45. Smith JH, Butterfield JH, Pardanani A, et al. Neurologic symptoms and diagnosis in adults with mast cell disease. Clin Neurol Neurosurg 2011.

46. Wehner F, Wehner HD, Fritz P, et al. [Sudden death in the presence of systemic mastocytosis and urticaria pigmentosa]. Arch Kriminol 2008;222:187-94.

47. Heide R, Van DK, Mulder PG, et al. Serum tryptase and SCORMA (SCORing MAstocytosis) Index as disease severity parameters in childhood and adult cutaneous mastocytosis. Clin Exp Dermatol 2009;34:462-8.

48. Krishnaswamy G, Ajitawi 0, Chi DS. The human mast cell: an overview. Methods Mol Biol 2006;315:13-34.

49. Shakoory B, Fitzgerald SM, Lee SA, et al. The role of human mast cell-derived cytokines in eosinophil biology. J Interferon Cytokine Res 2004;24:271-81.

50. Krishnaswamy G, Kelley J, Johnson D, et al. The human mast cell: functions in physiology and disease. Front Biosci 2001;6:D1109-D1127.

51. Fitzgerald SM, Lee SA, Hall HK, et al. Human lung fibroblasts express interleukin-6 in response to signaling after mast cell contact. Am J Respir Cell Mol Biol 2004;30:585-93.

52. Krishnaswamy G, Hall K, Youngberg G, et al. Regulation of eosinophil-active cytokine production from human cord blood-derived mast cells. J Interferon Cytokine Res 2002;22:379-88.

53. Krishnaswamy G, Lakshman T, Miller AR, et al. Multifunctional cytokine expression by human mast cells: regulation by $\mathrm{T}$ cell membrane contact and glucocorticoids. J Interferon Cytokine Res 1997;17:167-76.

54. Chi DS, Walker ES, Hossler FE, et al. Bacterial activation of mast cells. Methods Mol Biol 2006;315:383-92.

55. Hsieh CJ, Hall K, Ha T, et al. Baicalein inhibits IL-1beta- and TNF-alpha-induced inflammatory cytokine production from human mast cells via regulation of the NFkappaB pathway. Clin Mol Allergy 2007;5:5.

56. Lee SA, Fitzgerald SM, Huang SK, et al. Molecular regulation of interleukin-13 and monocyte chemoattractant protein-1 expression in human mast cells by interleukin-1beta. Am J Respir Cell Mol Biol 2004; 31:283-91.

57. Krishnaswamy G, Martin R, Walker E, et al. Moraxella catarrhalis induces mast cell activation and nuclear factor kappa Bdependent cytokine synthesis. Front Biosci 2003;8:a40-a47.

58. Tolar J, Tope WD, Neglia JP. Leukotrienereceptor inhibition for the treatment of systemic mastocytosis. N Engl J Med 2004;350:735-6.

59. Prignano F, Troiano M, Lotti T. Cutaneous mastocytosis: successful treatment with narrowband ultraviolet B phototherapy. Clin Exp Dermatol 2010;35:914-5.

60. Czarnetzki BM, Rosenbach T, Kolde G, et al. Phototherapy of urticaria pigmentosa: clinical response and changes of cutaneous reactivity, histamine and chemotactic leukotrienes. Arch Dermatol Res 1985;277:105-13.
61. Monahan TP, Petropolis AA. Treatment of telangiectasia macularis eruptiva perstans with total skin electron beam radiation. Cutis 2003;71:357-9.

62. Crawhall JC, Wilkinson RD. Systemic mastocytosis: management of an unusual case with histamine ( $\mathrm{H} 1$ and $\mathrm{H} 2)$ antagonists and cyclooxygenase inhibition. Clin Invest Med 1987;10:1-4.

63. Johnson GJ, Silvis SE, Roitman B, et al. Long-term treatment of systemic mastocytosis with histamine $\mathrm{H} 2$ receptor antagonists. Am J Gastroenterol 1980;74:485-9.

64. Cengizlier R, Hucumenoglu S, Ozen A, et al. Treatment of telangiectasia macularis eruptiva perstans with montelukast. Allergol Immunopathol (Madr) 2009;37: 334-6.

65. Ferkovic TJ, Lanese TR, Long BD. Use of oral cromolyn sodium in systemic mastocytosis. Clin Pharm 1982;1:377-9.

66. Soter NA, Austen KF, Wasserman SI. Oral disodium cromoglycate in the treatment of systemic mastocytosis. N Engl J Med 1979; 301:465-9.

67. Dolovich J, Punthakee ND, MacMillan AB, et al. Systemic mastocytosis: control of lifelong diarrhea by ingested disodium cromoglycate. Can Med Assoc J 1974;111: 684-5.

68. Kluin-Nelemans HC, Jansen JH, Breukelman $\mathrm{H}$, et al. Response to interferon alfa-2b in a patient with systemic mastocytosis. N Engl J Med 1992;326:619-23.

69. Yoshida C, Takeuchi M, Tsuchiyama J, et al. Successful treatment of KIT D816V-positive, imatinib-resistant systemic mastocytosis with interferon-alpha. Intern Med 2009;48:1973-8. 